\title{
BACTERIAL PROFILE AND THEIR ANTIMICROBIAL RESISTANCE PATTERN IN AN INTENSIVE CARE UNIT OF A TERTIARY CARE HOSPITAL IN DHAKA
}

\author{
Lovely Barai ${ }^{1}$, Kaniz Fatema ${ }^{2}$, J Ashraful Haq ${ }^{1}$, Mohammad Omar Faruq ${ }^{2}$, ASM Areef Ahsan ${ }^{2}$, \\ Md. Abu Hana Golam Morshed ${ }^{1}$, Md. Belayet Hossain ${ }^{1}$ \\ ${ }^{1}$ Department of Microbiology and ${ }^{2}$ Department of Critical Care Medicine, Bangladesh Institute of \\ Research and Rehabilitation in Diabetes, Endocrine and Metabolic Disorder (BIRDEM)
}

\begin{abstract}
Critically ill patients admitted in intensive care units (ICU) are always at a higher risk of developing infections with various antibiotic resistant organisms. The objective of this study was to know the antibiotic resistance pattern of the common isolates from blood, urine, respiratory secretions and pus/wound swab of patients admitted in ICU at BIRDEM (Bangladesh Institute of Research and Rehabilitation in Diabetes, Endocrine and Metabolic Disorder) hospital, during a one year period from March 2006 to February 2007. A total of 1660 samples were analyzed. Growth was obtained in $34 \%$ of the samples yielding 632 organisms. The major organism isolated were Pseudomonas sp. (29.1\%), Acinetobacter sp. (27.5\%), Candida sp. (12.8\%), Escherichia coli (10.3\%) and Klebsiella sp. (9.7\%). Staphylococcus aureus, Enterobacter sp, Citrobacter sp, Enterococcus sp, Providencia $s p$ and Serratia $s p$ accounted for $10.6 \%$ of the isolates. All the isolates were highly resistant $(>80 \%)$ to cephalosporins and fluoroquinolones. The frequency of third generation cephalosporin resistant E. coli, Klebsiella and imipenem resistant Pseudomonas and Acinetobacter were $>50 \%$. Acinetobacter was remarkably resistant to most antibiotics including imipenem ( $>70 \%$ resistant), but most of the members of the Enterobacteriacae group showed maximum sensitivity to imipenem (50\%-94\%). The findings of this study might help clinicians to formulate their first line empirical antibiotic treatment regimens for the patients admitted in ICUs.
\end{abstract}

Ibrahim Med. Coll. J. 2010; 4(2): 66-69

Key words: Intensive care units, antimicrobial resistance pattern, bacterial profile.

\section{Introduction}

Critically ill patients admitted in intensive care units (ICU) are always at a higher risk of developing nosocomial infections with resistant strains. ${ }^{1}$ Patients admitted in ICUs have an increased susceptibility to infection because of decreased mobility and increased use of invasive devices. ${ }^{2}$

Infection with resistant strains in the ICUs leads to increased mortality and cost. ${ }^{3}$ In ICU patients, the patterns of organisms causing infections and their antibiotic resistance differ widely from one hospital to other or one country to another, and even among
ICUs within one hospital. In addition, certain types of pathogens are becoming common in each local community and represent an important risk factor for the morbidity and mortality of ICU patients. ${ }^{4}$ In a study in an Indian ICU, the most common organisms were Acinetobacter sp, Escherichia coli, Klebsiella sp., Pseudomonas aeruginosa, Staphylococcus aureus, Streptococcus pyogen, etc. ${ }^{5}$ But in an European ICU, Staphylococcus aureus was found as the most frequently isolated organism (30.1\%) followed by Pseudomonas aeruginosa (28.7\%), coagulase negative staphylococcus $(19.1 \%)$ and yeast $(17.1 \%)^{6}$

\footnotetext{
Address for Correspondence:

Dr. Lovely Barai, Assistant Professor, Dept. of Microbiology, BIRDEM, 122 Kazi Nazrul Islam Avenue, Dhaka 1000. e-mail: barailovely@yahoo.co
} 
Bacterial profile and resistance

A knowledge of the antibiotic susceptibility of the organisms isolated in the ICU helps to formulate an antibiotic policy for the ICU. This also avoids unnecessary use of broad spectrum antibiotics and prevents emergence of drug resistant bacterial strains. ${ }^{7}$ The data on the changing antibiotic susceptibility trends is important for infection control activities in ICU settings. Presently, data on pattern of organisms and their antibiotic susceptibility in ICUs of large hospitals of our country are lacking. Therefore, the present study was undertaken to determine the pattern of organisms causing infection in ICU with their antibiotic sensitivity patterns over a one year period in a 600 bed tertiary care hospital of Dhaka city. This data may be useful to plan antibiotic guidelines as well as antibiotic cycling in ICU settings.

\section{Material and Methods}

The study unit was a 10 bed closed combined ICU of BIRDEM hospital. All the samples obtained for culture and sensitivity tests from patients admitted in ICU during March 2006 to February 2007 were included in the study. Samples included blood, urine, sputum/ tracheal aspirate (respiratory secretions) and pus/ wound swabs. The samples were cultured in standard media for isolation of potential pathogens. Isolates were identified by standard methods. ${ }^{8}$ For each isolates antibiotic susceptibility was performed by Kirby Bauer disk diffusion techniques. ${ }^{9}$ Isolates with intermediate susceptibility were considered resistant.

\section{Results}

A total of 1660 samples were analyzed which included blood (811), urine (372), respiratory secretions (448) and pus or wound swab (29). Out of 1660 samples, organisms were isolated from 564 samples (Table 1).

Table 1: Sample profile and rate of positive culture from different samples

\begin{tabular}{l|r|r|r}
\hline Samples & $\begin{array}{l}\text { Total No. } \\
\text { sample }\end{array}$ & \multicolumn{2}{|c}{$\begin{array}{c}\text { Samples yielding growth } \\
\text { of organisms }\end{array}$} \\
\cline { 3 - 4 } & & \multicolumn{1}{|c}{ N } & \% \\
\hline Blood & 811 & 87 & 10.7 \\
Urine & 372 & 150 & 40.3 \\
Resp. secretions & 448 & 305 & 68.1 \\
Pus/wound swab & 29 & 22 & 75.8 \\
\hline Total & 1660 & 564 & 34.0 \\
\hline
\end{tabular}

Table 2: Pattern of organisms isolated from different samples

\begin{tabular}{lcc|c|c|c|c}
\hline Organisms & Blood & Urine & $\begin{array}{c}\text { Resp } \\
\text { sec. }\end{array}$ & $\begin{array}{c}\text { Pusl } \\
\text { WS }\end{array}$ & $\begin{array}{c}\text { Total } \\
(\%)\end{array}$ \\
\hline $\begin{array}{l}\text { Non fermenter organism } \\
\text { Pseudomonas sp. }\end{array}$ & 45 & 17 & 116 & 06 & $184(29.1)$ \\
$\begin{array}{l}\text { Acinetobacter sp. } \\
\text { Enterobacteriaceae }\end{array}$ & 16 & 08 & 144 & 06 & $174(27.5)$ \\
$\begin{array}{l}\text { E coli } \\
\text { Klebsiella sp. }\end{array}$ & 14 & 33 & 16 & 02 & $65(10.3)$ \\
Enterobacter sp. & 05 & 14 & 38 & 04 & $61(9.7)$ \\
Serratia sp. & 02 & 05 & 12 & 02 & $19(3.0)$ \\
Providencia sp. & 01 & 07 & 00 & 00 & $02(0.3)$ \\
Citrobacter sp. & 02 & 00 & 00 & 00 & $02(0.3)$ \\
Gram positive cocci & & & & & \\
$\quad$ Staph aureus & 00 & 01 & 08 & 00 & $09(1.4)$ \\
Coag NS & 00 & 02 & 00 & 00 & $02(0.3)$ \\
Enterococcus sp. & 00 & 10 & 01 & 00 & $11(1.7)$ \\
Fungus & & & & & \\
Candida sp. & 02 & 74 & 05 & 00 & $81(12.8)$ \\
\hline Total & 87 & 171 & 352 & 22 & 632 \\
& $(13.7)$ & $(27.1)$ & $(55.7)$ & $(3.5)$ & \\
\hline
\end{tabular}

Note: Many samples yielded more than one organism. Resp sec: respiratory secretions, WS: wound swab, Coag NS: coagulase negative staphylococcus

The commonest organism isolated from all samples was Pseudomonas sp. 184 (29.11\%) followed by Acinetobacter sp. 175 (27.5\%), Candida sp. 81 (12.8\%), Escherichia coli 65 (10.3\%) and Klebsiella sp. 61 (9.6\%). Table 2 shows the detail pattern of organisms isolated from various types of samples.

Table 3: The antibiotic resistance pattern of major organisms isolated from the patients in intensive care units.

\begin{tabular}{l|c|c|c|c}
\hline \multirow{2}{*}{ Antibiotics } & \multicolumn{4}{|c}{ Percent isolates showing antibiotic resistance } \\
\cline { 2 - 5 } & $\begin{array}{c}\text { Pseudomonas } \\
s p\end{array}$ & $\begin{array}{c}\text { Acinetobacter } \\
\boldsymbol{s} \boldsymbol{p}\end{array}$ & $\boldsymbol{E}$ coli & $\begin{array}{c}\text { Klebsiella } \\
\boldsymbol{p} \boldsymbol{p}\end{array}$ \\
\hline Â-lactam & & & & \\
Piperacillin & 73.8 & 100 & - & - \\
Ceftriaxone & 95.6 & 98.2 & 92.2 & 93.0 \\
Ceftazidime & 81.5 & 95.3 & 87.9 & 94.9 \\
Cefotaxime & 96.6 & 100 & 73.1 & 97.2 \\
Aztreonam & 82.4 & 91.6 & - & - \\
Imipenem & 57.6 & 72.4 & 4.6 & 21.3 \\
Aminoglycosides & & & & \\
Amikacin & 62.5 & 81.4 & 48.3 & 53.7 \\
Netilmicin & 76.4 & 77.9 & 71.7 & 55.9 \\
Gentamicin & 90.3 & 93.2 & 74.6 & 73.7 \\
Quinolones & & & & \\
Ciprofloxacin & 80.2 & 94.6 & 98.1 & 88.5 \\
Others & & & & \\
Cosptrimoxazole & 91.9 & 96.4 & 81.3 & 95.1 \\
Tetracycline & 97.4 & 91.6 & 80.8 & 83.3 \\
\hline
\end{tabular}


Major organisms isolated from blood were Pseudomonas sp. (51.7\%) and Acinetobacter sp. (18.4\%) while from urine it was Candida sp (43.3\%) and $E$. coli $(19.3 \%)$. The most frequently isolated organisms from both respiratory secretions and pus were Acinetobacter sp. (40.9\% and $27 \%$ respectively) and Pseudomonas sp. (32.9\% and $27 \%$ respectively).

The antibiograms of common isolates are shown in Table 3. Majority of the isolates were resistant to $3^{\text {rd }}$ generation cephalosporins and ciprofloxacin $(>80 \%)$. The frequency of third generation cephalosporin resistant E. coli and Klebsiella and imipenem resistant Pseudomonas was more than 50\%. Enterobacteriacae group showed maximum sensitivity to imepenem but $>70 \%$ Acinetobacter was resistant. Acinetobacter was remarkably resistant to most antibiotics. Resistance pattern of organism to aminoglycosides was variable ranging from 48.3 to $93.2 \%$.

About $77 \%$ of isolated S. aureus were methicillin resistant (MRSA).

\section{Discussion}

Our study included types and antibiotic susceptibility pattern of organisms isolated from different samples from critically ill patients, but it did not attempt to investigate the underlying disease condition of patients or their sources of infection.

In this study, about $55.7 \%$ of the organisms were isolated from respiratory secretions (sputum and tracheal aspirate) which probably were due to the fact that most patients either had prior respiratory problems or were in ventilators.

Gram negative bacteria were isolated at a significantly higher rate $(84 \% ; \mathrm{p}<0.05)$ than gram positive bacteria and Candida. Pseudomonas, Acinetobacter, E. coli, Klebsiella and Candida were the most prevalent pathogens recovered from our ICU patients (Table2). The predominant bacterial isolates reported in the Jordanian, Indian and European studies were almost similar to our results. ${ }^{3,5,10}$

Reduction in antimicrobial resistance in the ICUs has been a goal for all intensive care units as it improves the outcome and reduces total expenses as well as duration of ICU stay. The extreme antibiotic use results in the emergence of multi-resistant microorganisms in the ICU environment. The present study revealed high prevalence of antibiotic resistant organisms in our ICU. More than $75 \%$ Pseudomonas $s p$. showed resistance to third generation cephalosporins and fluoroquinolons. In 2005, a study conducted in the same ICU reported $82 \%$ of Pseudomonas as resistant to third generation cephalosporins. ${ }^{11}$ But it has been observed that the frequency of fluoroquinolon and imipenem resistant Pseudomonas (79.1\% and 58.9\%) has increased in the present study compared to that of 2005 (48\% and 36\% respectively).

Acinetobacter sp was the second commonest (27.7\% of all isolates) organism isolated from all samples. Though this is commonly isolated from skin and throat of healthy people, it is also known to colonize respirators, respiratory tubing and intravenous catheters in ICU causing serious and often fatal opportunistic infections. They are generally resistant to most classes of antimicrobials and emergence of imipenem resistant strains in many parts of the world is alarming and a threat to the effective management of these infections. ${ }^{12}$ In our study, Acinetobacter was remarkably resistant to most antibiotics including imipenem (64.2\%). E. coli, Klebsiella and Enterobacter isolates were maximally susceptible to imipenem ( $>75 \%$ sensitive). The susceptibility of these bacteria to cephalosporins was uniformly poor in our study ( $>80 \%$ resistant). This was probably due to over use of cephalosporins in the indoor and ICU patients. Resistance pattern of these organisms to aminoglycosides showed marked variability ranging from $48.3 \%$ to $83.3 \%$.

Candida species was the third frequently isolated organism in our ICU. Both C. albican and non- albican Candida species were found. Most were isolated from urine. High number isolation of Candida might be due to the presence of underlying conditions like poor nutritional status, diabetes mellitus and the use of steroids and broad spectrum antibiotics.

\section{References}

1. Singh AK, Sen MR, Anupurba S, Bhattacharya P. Antibiotic sensitivity pattern of the bacteria isolated from nosocomial infections in ICU. Journal of Communicable Diseases 2002; 34: 257-263.

2. Rice LB. Controlling antibiotic resistance in the ICU: Different bacteria, different strategies. Cleveland Clinic Journal of Medicine 2003; 70: 793-800. 
3. Kaul S, Bahmadathan KN, Jagannati M, Sudarsanam TD, Pitchamuthe K, Abraham OC et al. One year trends in the gram negative bacterial antibiotic susceptibility patterns in a medical intensive care unit in South India. Indian J Med Microbiology 2007; 25: 230-5.

4. Shehabi AA, Baadran I. Microbial infection and antbiotic resistance patterns among Jordanian intensive care patients. Eastern Mediterranean Health Journal 1996; 2: 515-520.

5. Patwardhan RB, Dhakephalkar PK, Niphadkar KB, Chopade BA. A study on nosocomial pathogens in ICU with special reference to multiresistant Acinetobacter baumannii harbouring multiple plasmids. Indian J Med Res 2008; 128: 178-187.

6. Spencer RC. Predominant pathogens found in the European prevalence of infection in intensive care study. Eur J Clin Microbial Infect Dis 1996; 15: 281-5.

7. Tullu MS, Deshmukh CT, Baveja SM. Bacterial profile and antimicrobial susceptibility pattern in catheter related nosocomial infections. J Postgraduate Med 1998; 44: 7-13.

8. Colle JG, Miles RS, Watt B. Tests for the identification of bacteria. In: Mackie \& McCartney Practical Medical Microbiology, $14^{\text {th }}$ edn. New York. Churchill Livingstone Inc, 1996; 131-149.

9. Bauer AW, Kirby WMM, Sherris JC, Tierch M. Antibiotic susceptibility testing by a standardized sigle disc method. Am J Clin Pathol 1966; 45: 493-9.

10. Verbist L. Epidemiology and sensitivity of 8625 ICU hematology/ oncology bacterial isolates in Europe. Scand J Infectious Disease 1993; Supplementum 91:14-24.

11. Basunia MRA, Rahman MR, Faruq MO, Huq F, Ahsan A, Hasan R, Ahmed B. Microbial pathogens and antibiotic sensitivity at intensive care unit of BIRDEM: A retrospective study. Bangladesh $J$ Medicine 2005; 16: 14-20.

12. Mulvey MR, Simor AE. Antimicrobial resistance in hospitals: How concerned should we be? Canadian Med Assoc J 2009;180: 408-415. 